\author{
S. Y. Erinosho, M. N. Femi-Oyewo \& E. O. Oduwole
}

\title{
Sexual Harassment on Campus: A Study in a Nigeria University
}

\begin{abstract}
Sexual harassment (SH) is increasingly reported as an issue of major concern among both students and staff on campuses across the globe, and has been confirmed to have social and psychological consequences on the victim. However, the scale of the menace is underplayed because of under-reporting of cases. As a way to containing and/or regulating the behaviour, it is therefore imperative to obtain credible evidence on the veracity, the different forms, and how they play out to affect student victims with a view to foster an equitable campus climate. Thus, against the magnitude of the anecdotal reports on $\mathrm{SH}$ and the absence of empirical evidence on its extent, this study is concerned with obtaining baseline data on the forms and prevalence of campus-based sexual harassment, as well as ascertaining the awareness and knowledge of SH among undergraduates in a Nigeria University (OOU). An exploratory study involving cross-sectional survey of 1420 males and females was undertaken cutting across the faculties and levels in the University. The findings confirmed the existence of sexual harassment in OOU campus, though reported not to be on a rampant scale. Also, the behavior elements that indicate features of a hostile-environment harassment were reported with most likely occurrence on the campus. The policy implications of the findings were highlighted and recommendations made towards the prevention of SH victimization on the University campus.
\end{abstract}

\section{Introduction}

In recent time, there has been an increasing concern about the problem of sexual harassment of students on campuses. Indeed, the evidence suggest that campuses are becoming notoriously unsafe and hostile ground, rather than provide protected environment where students would acquire knowledge and develop healthy life-long mutual friendship in a respectful atmosphere. There is abundance of studies in several countries that identified sexual harassment $(\mathrm{SH})$ as a common form of gender-based discrimination routinely encountered by students (in particular, women) in their everyday lives on campus. For example, a nationwide survey of female students' experience of violence in UK campuses found that one in four respondents had experienced unwanted sexual behavior (Biden, 2010). Similar reports were expressed by Taylor \& Hardin (2017) in USA; Steinkamp (2010) in South Africa; Norman, Aikins, \& Binka, (2013) in Ghana; Mamaru,, Getachew, \& Mohammed (2015) in Ethiopia; and Nwagbara (2011) in Nigeria. Both boys and girls are victims of sexual misconduct, though in many instances, experience of sexual victimisation are more common among women than men (Mitchell, Ybarra, \& Korchmaros, 2014). There are reported cases of male staff taking advantage of their superior position, or their economic superiority to lure, coerce or sexually intimidate girls. In some instances, male students are found to sexually intimidate fellow female students (Kheswa, 2014).

However, data on the prevalence of campus-based sexual harassment has remained circumscribed because of under-reporting of cases. Rather than reporting, victims would maintain silence or avoid the harasser out of fear or embarrassment (Cortina \& Wasti, 2005). According to Dziech \& Weiner (in the book Lecherous Professor cited in Smit and Plessis, 2011):

sexual harassment by university professors of their female students is a fact of campus life and that the silencing thereof is part of the reason for the historical invisibility of the problem: silence, promoted by the fear that somehow they (the victims) are responsible for the sexual harassment in one way or the other, and/or the fact that students know they are subordinate to faculty staff and administrators. 
As a way to maintain a safe and healthy educational environment, responsible institutions have developed policy measures, and in some cases criminalise $\mathrm{SH}$ behaviours. In USA for instance, $\mathrm{SH}$ is a form of sex discrimination prohibited in schools by Title IX, a Federal law in the US establishing civil rights in education (U.S. Department of Education, Office for Civil Rights, 2001). University of Vermont (2015) Policy document on sexual harassment and misconduct strictly prohibit sexual misconduct including "sexual assault, relationship violence, stalking based on sex or gender... Sanction may include suspension or dismissal from University, termination from employment, prosecution under the law ..." A similar effort to address the problem at the University of Ibadan culminated in the Sexual Harassment Policy document approved by Senate in 2012 (http://www.ui.edu.ng/news / sexual-harassmentpolicy)...any person found liable of perpetrating sexual harassment, falsely accusing any person or instigating the occurrence of false accusation shall be subject to penalty..

Campus sexual harassment is not newly occurring in Nigeria; it has been in existence for long, although not given due prominence. There was a groundswell of interest to explore issues of sexual harassment in Nigeria higher education in the early 2000s when the system suffered the crisis of unprecedented moral collapse for many reasons. Studies that were conducted on campuses across the country confirmed the high prevalence of different forms of sexual misconduct. Unfortunately, despite the findings from the studies, not many Universities used the cues to frontally address the problem and develop policy measures to regulate, and/or sanction the behaviour. Consequently, it has remained a serious but insufficiently addressed problem.

There is no doubt that campus-based sexual harassment and/or sexual misconduct deserve serious attention, not just for the offensive nature of the behaviour, but more importantly because of the social and psychological consequences on the victim. Moreover, the consequence of sexual harassment limits the right to receive an equal educational opportunity, and could constitute drawback for the victim, (in particular girls) towards realization of their academic attainment as well as personal development.

\section{Statement of Problem}

The reality of the OOU campus shows clearly the high risk environment under which students learn. It is largely nonresidential campus, whereby students live together in shared apartments, having to negotiate relationships with the opposite sex, including male staff/students and significant others within the community. There are insinuations that the harsh economic and social realities predispose students to sexual harassment victimization by unethical lecturers who tried to exploit the situation. It is against the magnitude of the anecdotal reports on $\mathrm{SH}$ and the absence of empirical evidence on its extent that this study is concerned with ascertaining the seriousness of sexual harassment on OOU campus from the perception of students. The study attempted to identify its veracity, the different forms, and how they play out against students with a view to enabling the University with empirical data for development of the Policy on Sexual Harassment and initiating institutional support system for victims.

\section{Objectives of the Study}

The objectives of the study are to:

1. Obtain baseline data on the forms and prevalence of campus-based sexual harassment on OOU Campus;

2. Ascertain the level of awareness and knowledge of $\mathrm{SH}$ among undergraduates in OOU as it relates to campus-based sexual harassment.

\section{Research Questions}

Two major questions guided the study:

(1) What are the forms and prevalence of $\mathrm{SH}$ that are commonly experienced by students on OOU campus?

(2) What would be the perception of students to situations involving sexual harassment behaviour in terms of occurrence and awareness of $\mathrm{SH}$ behaviour?

\section{Literature Review \\ Definitions of Sexual Harassment}

Despite the growing interest in the study of $\mathrm{SH}$ over the years, the fact that no single definition of the phenomenon has evolved continue to pose limitation towards addressing the problem. The literature is inundated with different conception of sexual harassment, covering a broad spectrum of behaviour encompassing simple jokes about looks or touching to more serious sexual assault/rape. The various definitions of sexual harassment have focused on wide variety of specific behaviors according to how it is presented to the victim and the context that it occurred (Till, 1990; Gruber, \& Fineran, 2000; Pina, Gannon, \& Saunders, 2009; Kaltiala-Heino et al., 2016; Herrera \& Expósito, 2017). For example, Till (1990) identified five classifications as:

(a) general harassment - behavior that convey insulting, degrading or sexist attitude;

(b) seductive behavior - inappropriate and offensive sexual advances:

(c) sexual bribery - solicitation of sexual activity and other sex-related behaviour by promise or reward;

(d) sexual coercion - sexual activity by threat or punishment;

(e) sexual imposition or assault - sexual crimes and misdemeanor including rape and assault.

Sandler \& Shoop (1997) condensed this behavior types to three, including any request for sexual favours that 
(a) submission to such conduct is either explicitly or implicitly made a term or condition of academic achievement,

(b) submission to or rejection of such conduct is used as the basis for academic decisions, and

(c) such conduct has the purpose or effect of unreasonably interfering with a person's academic performance or create an intimidating, hostile or offensive learning environment

Kastil \& Kleiner, (2001) and Bauemeister (2001) further condensed the behavior into two broad areas as: quid pro quo - exchange of one thing for another, e.g., sex for reward or threat; and hostile working and learning environment. A quid pro quo harassment usually takes place in educational settings "when a school employee explicitly or implicitly conditions a student's participation in an education program or activity or bases an educational decision on the student's submission to unwelcome sexual advances, requests for sexual favors, or other verbal, nonverbal, or physical conduct of a sexual nature e.g when a student is coerced into having sexual relationship with a lecturer under the threat of failing a course or promise of pre-knowledge of examination questions or rewards of favourable grades. A fellow student could also harass his/her peer under the same condition. On the other hand, a hostile learning environment is one in which a female/male student is subjected to repeated offensive and denigrating sexual comments and behaviour which can include unwelcome sexual advances, requests for sexual favours and other verbal, nonverbal, or physical conduct of sexual nature by lecturer, another student, or a third party that is sufficiently severe, persistent, or pervasive to limit a student's ability to participate in or benefit from an education program (Willness, 2007). Studies show that, in school settings and particularly between students, allegations of hostile-environment harassment are more commonplace than allegations of quid pro quo harassment (Stein, 2000).

Other classifications suggested three forms of sexual harassment: gender harassment, unwanted sexual attention and sexual coercion (Schneider, Pryor, \& Fitzgerald, 2010; Buchanan et al., 2013). Gender harassment comprises verbal and non-verbal gender-based hostile/derogatory communication or gender related name-calling that convey insulting, hostile and degrading attitudes about the individual; unwelcome sexual attention includes any sexual behaviour, propositions, invitations, etc, which are distasteful and unwelcome to the target and perceived as offensive; while sexual coercion includes actual sexual assault and any behaviour that connotes extortion of sexual cooperation in return for promises/benefits or threats, e.g., a lecturer withholding students' examination results or threatening to fail as precondition for sexual activity. Unwanted sexual attention includes any bodily behaviour and gestures that are deliberately used to arouse sexual attention in an offensive way.
Education institutions provided more explicit variety of specific behaviours that constitute sexual harassment. For example, The American Association of University Women identified sexual harassment in a school setting to include the following unwanted or unwelcome behaviors from other students or adult school personnel: sexual comments, jokes, gestures, rumors or looks; showing of sexual pictures, photographs, illustrations; written sexual messages, notes or graffiti on bathroom walls or locker rooms; being called gay or lesbian in a malicious manner; spied on while dressing or showering at school; 'flashed' or 'mooned' by someone; touched, grabbed, or pinched in a sexual way; clothing pulled off or down in a sexual way; intentionally brushed up against by someone in a sexual way; blocked or cornered in a sexual way; and, forced to kiss someone, or experience some other unwelcome sexual behavior other than kissing (AAUW 2001). Similarly, the University of Massachusetts defined sexual harassment in its regulations as follows:

Unwelcome sexual advances, requests for sexual favours and other verbal or physical conduct of a sexual nature constitute sexual harassment when:

(1) submission to such conduct is made either explicitly or implicitly a term or condition of an individual's employment or academic work,

(2) submission to or rejection of such conduct by an individual is used as the basis for employment or academic decisions affecting such individual, or

(3) such conduct has the purpose or effect of unreasonably interfering with an individual's work performance or creating an intimidating, hostile or offensive working or academic environment.

According to Harvard Law School Policy (2014), gender-based harassment include:

... verbal, nonverbal, graphic, or physical aggression, intimidation, or hostile conduct based on sex, sexstereotyping, sexual orientation or gender identity, but not involving conduct of a sexual nature, when such conduct is sufficiently severe, persistent, or pervasive that interfere with or limits a person's ability to participate in or benefit from the University's education or work programs or activities.

The University of Ibadan Policy on SH document

listed sexual harassment behaviours as:

- Unwanted sexually motivated conduct, comments, touching and expressions capable of prejudicing or undermining a person's freedom, rights and privileges. Such acts could include but are not limited to outright demands, ogling, indecent comments and unnecessary bodily contact which could lead to psychological or physical unsolicited sexual relationships;

- Unwanted suggestive looks, phone calls or use of other multimedia format and comments intended to lure a person into a sexual relationship;. 
- Spousal abuse where one or both partners are members of the University community.

Regardless of the different ways of describing $\mathrm{SH}$, researchers agree that the phenomenon encompasses any form of unwanted sexual behavior that is offensive or injurious to the victim, which may be one-time or persistent. It covers a range of activities, some of which are criminal (such as rape or sexual assault, battery), physically abusive behaviours ( e.g., threats, fondling ), verbal (e.g., making derogatory comments, spreading rumours, demanding for sexual favours in exchange for rewards etc.), non- verbal (e.g. unwelcome touching, hugging, kissing, caressing, blocking the way in sexual manner), non-touching actions (such as dirty jokes, leering, repeatedly asking for a date etc.), visual (e.g., sending unwholesome pictures, pornography, seduction with indecent dressing). In all cases of $\mathrm{SH}$, the action is unwanted, offensive, non-consensual and delimiting for the victim, may be from a superior to a subordinate or vice versa or among peers. It can be direct or indirect (including procuring or attempting to offer a person to another for sexual activity); and may involve persons of the same or opposite sex.

\section{Consequences of Sexual Harassment}

Sexual harassment behaviour usually is a manifestation of power play, with the perpetrator taking advantage of their superior position, or their economic superiority to lure, coerce or sexually intimidate victims (Kheswa, 2014) and may involve persons of the same or opposite sex (Pina, Gannon, \& Saunders, 2009). It presents a psychological experience that is offensive, devaluing and threatening (Topa, Morales, \& Depolo, 2008; Pina et al., 2009), perceived to negatively impact on the victims ability to participate in and beneût from educational programme, and create a hostile and offensive work/school environment (Gruber \& Fineran, 2007; Pina et al., 2009) as well as presents traumatizing experience for those who are victimized (Fineran \& Bolen, 2006). Sexual harassment can damage students' well-being, provoke and exacerbate conflict among students, contribute to a hostile learning environment and negatively influence schoolwork and performance (Hill \& Silva, 2005; (www.aauw.org 2-3).

\section{Incidence of Sexual Harassment}

Sexual harassment in the education sector is increasingly reported as an issue of major concern among both students and staff on campuses and schools (Hill and Silva, 2005; (Hill \& Kearl, 2011; Smit \& Plessis, 2011; Vega-Gea, Ortega-Ruiz,CLAVE, Sánchez, 2015; Harding, 2017)). The AAWU (2001) survey of 2063 American public school students in grades 8 to 11 reported the increasing rates of different forms of sexual harassment. The findings reported $81 \%$ had experienced sexual harassment at school; 83 per cent for girls and 79 per cent for boys reporting harassment; over $50 \%$ of male and female students experienced sexual comments, jokes, gestures or looks while over $30 \%$ of boys and girls experienced being touched, grabbed, pinched or brushed up against in a sexual way from schoolmates. Additionally, the AAUW survey in 2010-2011 school year found that about $48 \%$ of U.S. students nationwide in grades 7-12 reported experiencing some form of sexual harassment while in school.

Also in the USA, Petersen \& Hyde (2009) reported an increase in sexual harassment victimization as the adolescents grew older: of girls (boys) in 5th grade $35 \%$ $(55 \%)$, in the seventh grade $55 \%(68 \%)$, and in the 9 th grade $65 \%(78 \%)$ had experienced any of the elicited nine sexually harassing behaviours during the past year. Similar findings were reported by Espekhage \& Holt (2007) in a study among middle and high school students. The findings indicate that $81 \%$ of students experienced some form of sexual harassment during their school lives; 6 out of 10 experienced it occasionally, and a quarter of them dealt with sexual victimisation most of the time. McMaster et al., (2002) in Canada likewise reported experience of sexual harassment in $38 \%$ of girls and in $42 \%$ of boys in elementary/middle school, with increasing victimization in higher grades. Other studies reported findings of increased subjection to sexual harassment in school (Witkowska \& Menckel, 2005 in Sweden; Dhlomo et al., 2012 in Zimbabwe).

There is growing evidence of sexual harassment on campuses. Bannar-Kidd (2010) reported that in USA about 300,000 women are raped and 3.7 million are confronted with unwanted sexual activity annually. Also, Biden (2010) reported in a nationwide survey of female students' experiences of violence in UK that one in four had experienced unwanted sexual behavior in their stay on campuses. At Jimma University in Ethiopia, violence, harassment and lack of security were cited as the most common problems women students faced. In the study of 385 women at the University, Mamaru, Getachew \& Mohammed (2015) found that $78.2 \%$ of the respondents had experienced different forms of harassment. At the University of Dar Es Salaam, Tanzania, female students were reportedly being tortured by a secret group of members of the university, presenting them in sexually derogatory manner or publicized rudely after being raped to the extent that some of the cases committed suicide (FAWE News, 2000). A study by Twinama (2008) in Uganda informed that sexual harassment is prevalent, majorly perpetuated by male lecturers against female students and often referred to as "carpet grades" to signify the place of sexual transaction.

Other studies in South Africa (Dastile, 2004; Steenkamp, 2010); Zimbabwe (Dhlomo et al., 2012); Tunisia (Lynch, 2013); Ghana (Norman, Alkins \& Binta, 2013) all confirmed the prevalence of sexual harassment, and almost non-existent interventions to address the problem. Of noteworthy is the report of Dastile (2004) on University of Venda in South Africa, citing the case of a "female student class representative who was sexually harassed by the lecturer when she went to call the lecturer for a lecture...the lecturer reportedly touched, hugged and kissed her in his office and this happened more than once". 
Several other recent studies also confirmed the prevalence of sexual harassment in Nigeria tertiary institutions (Nwagbara, 2011; Imonikhe, Aluede, \& Idogho, 2012; Omonijo et al., 2013; Taiwo, Omole \& Omole, 2014). Omonijo focused on three faith-based private Universities and found that apart from the high scale of sexual harassment, many students did not report to authorities.

Additionally, media reports on several cases of sexual misconduct suggest that the problem is spreading in schools and tertiary institutions. For example, in 2016, the Management at the Federal Polytechnic, Bida reportedly suspended a lecturer in the Department of Public Administration for allegedly raping an ND1 student in the department. (http://www.pulse.ng/communities/student/bida-polylecturer-suspended-for-raping-student-id5001958.html); a lecturer at the University of Lagos, (UNILAG) was reported to have raped an 18 year old female admission seeker (apparently her father's friend) in a classroom under the guise of helping her secure admission into the University; a Dean of Law at the University of Calabar allegedly raped a 21 year old 400 level Law student of the institution. Worthy of mention is the sensational scandal case at Queens College, Lagos where a parent of a JSS2 girl claimed that "one of the male teachers in the school had allegedly molested her daughter on a few occasions, after the teacher had been around the hostel at night, while he was drunk."

In the backdrop of the wave of complaints and accusations, a Bill on Sexual Harrassment in Tertiary Education was presented at the floor of National assembly to be passed into law criminalising sexual misconduct involving lecturers and students...prescribing 5 year jail term for offenders.

The Bill reportedly received strong support from members of the Nigerian Female Students Association as they stormed the National Assembly (Senate) Abuja, to show their unflinching support to the Bill for a law prescribing five-year jail term for lecturers sexually harassing female students. President of the association...expressed great delight that the Bill has passed through second reading in the floor of Senate... added that a lot of female students have dropped out of school, end up with low grades while some fail course... the growing abuse of female students is orchestrated by lack of consistent and clear policy by school governing bodies and school authorities concerning sexual harassment http://www.pulse.ng/communities/student/sexua 1-harassment-female-students-storm-nigeriansenate-id5093183.html

\section{Methodology}

The study adopted a cross-sectional descriptive survey design. A total of 1408 students participated in the The Campus Climate Survey on Sexual harassment drawn from the 8 Colleges/Faculties of OOU: Education, 26.4\%; Social and
Management Sciences 19.2\%, Law 8.7\%; Arts 13.0\%; Medicine/Pharmacy, 8.7\%; Sciences, $12.0 \%$; Agricultural Sciences, $8.5 \%$; and Engineering 3.6\%. The majority of respondents are females ( $71.8 \%)$, aged between $16-25$ years (90\%), entered the university after $2014 / 15$ session (69.8\%), single (88.4\%) and living in rented apartment (95.6). A subsample of 302 students answered questions on hypothetical scenarios involving forms of $\mathrm{SH}$ to ascertain their perception of $\mathrm{SH}$ and their anticipated responses to such situation.

Data collection instruments consisted of The Campus Climate Survey questionnaire and the Scenario perception questionnaire. The climate survey questionnaire provided students with a 16-item list of $\mathrm{SH}$ behavior and asked students to indicate how often they had experienced each of the acts since joining the university on a format of 3 -point scale (often $=3$, sometimes $=2$, never $=1$ ). The perception questionnaire administered to a sub sample of the students consists of 10-item hypothetical scenarios to debrief the students on their perception of the likelihood of action in the scenarios occurring in OOU and the prevalence of occurrence of such behavior on a format scale of most likely, maybe, not at all.

For the perception questionnaire, each respondent was presented with descriptions of scenarios that connote possibility of sexual harassment between lecturer and student or student-student. Each of the descriptions presented for judgment had specific elements of $\mathrm{SH}$ put together to construct a potential action initiated by someone in authority or superior position, either lecturer to student or student to student. The focus of the harassment descriptions are on students. Eight constructs were formed from all the descriptions and each construct has elements of sexual harassment contained in the descriptions. The constructs are:

Construct 1: Setting - indicating where the action was initiated e.g., office, hostel, classroom.

Construct 2: Status indicating gender and level of study or professional status.

Construct 3: Initial Actions, indicating the victim's initial response e.g., shocked, ignored, played it down.

Construct 4: Baits, indicating the initial actions taken to attract the victim, e.g., raised issue about assignment, requested to assist in recording marks, asked to collect registration forms for the class.

Construct 5: Verbal Behaviors, indicating spoken actions e.g., "I like you, be my good girl, jokingly said "You are beautiful", tells her I like your red bra, invite her for lunch.

Construct 6: Physical Actions, indicating responses and stimuli that are physical and non-verbal e.g., locked the door, moved close towards her, grabbed her dress, send love texts persistently.

Construct 7: Threats/Reward, indicating the actions taken as enticement/force for $\mathrm{SH}$, e.g., promise to help with project, threaten to blackmail if he says it out, promise her " $A$ " if she would allow him feel her body, she told him the boys are waiting outside to deal with you.

Construct 8: Response/Action taken, indicating what the victim did, e.g., conceded the request, cried, avoided class, kept to herself. 
The instruments were administered as in-class activity by research assistants. Students were targeted with the permission of course lecturers in compulsory courses cutting across the different levels. Random sample of students, mostly those that willingly volunteered to participate after explaining the objectives of the study to them, were involved in the completion of the questionnaire. The students were informed that their responses to the questionnaires would remain anonymous and did not have to divulge their identity. Both sets of the questionnaire were randomly distributed for completion. The data were subjected to descriptive analyses using SPSS tools and quantified using percentages and mean.

\section{Findings}

A total of 849 respondents $(60.1 \%)$ are of the opinion that there is $\mathrm{SH}$ on OOU campus, out of which $27.4 \%$ described the behavior as very rampant and $32.6 \%$ felt it is existing but not as bad. As many as a quarter among the sampled students $(25.8 \%)$ are not sure that it is existing while $10.4 \%$ claimed not to have heard about it. A high percentage of the students claimed to have formed their opinion more from what they heard people talk (55.8\%), what they see others experienced (19.5\%) and least from personal experience (11.1\%)

Even though the numbers in Table 1 indicate that the majority never experienced the eighteen $\mathrm{SH}$ actions that were presented, those who reported $\mathrm{SH}$ victimization experiences are significant enough for consideration. Using the reported frequency of occurrence of the SH behaviour, the most frequently experienced items were "make annoying jokes about looks" $(\bar{x}=1.46)$. Other noteworthy victimization items with high occurrence are "touch intimate body part in disrespectful way" $(\bar{x}=1.40)$, "pass comment about look that is sexual" $(\bar{x}=1.31)$ and ask for outing and you say no" $(\bar{x}=1.26)$. The behavior that fewer students reported to have experienced were: "send embarrassing phonographic photos" $(\bar{x}=0.97)$, deceive to unsafe place for $\operatorname{sex}(\bar{x}=1.05)$, forced to intimate relationship against will $(\bar{x}=1.07)$ and Circulate false sexual rumors about you $(\bar{x}=1.85)$.

Table 1: Mean scores to $\mathrm{SH}$ victimization experience by lecturers

\begin{tabular}{|l|lllll|}
\hline Has any lecturer: & Often & Sometimes & Never & N & $\bar{x}$ \\
\hline Touch intimate body in disrespected way & 128 & 186 & 804 & 1118 & 1.40 \\
Peck/kiss in embarrassing way & 53 & 69 & 1024 & 1146 & 1.15 \\
Make annoying jokes about look & 202 & 140 & 830 & 1172 & 1.46 \\
Make overtures for sexual affair & 84 & 128 & 954 & 1166 & 1.25 \\
Block you to touch body to your annoyance & 20 & 43 & 1053 & 1116 & 1.17 \\
Deceive to unsafe place for sex & 8 & 43 & 1068 & 1119 & 1.05 \\
Offer grade or money reward for date & 93 & 107 & 876 & 1076 & 1.27 \\
Force to intimate relationship against will & 14 & 55 & 1070 & 1139 & 1.07 \\
Asking for love advances when you say N0 & 106 & 60 & 958 & 1124 & 1.24
\end{tabular}

\begin{tabular}{|l|lllll|} 
Threaten to have sex or fail a course & 41 & 63 & 1072 & 1172 & 1.13 \\
Demand sexual relationship for grade & 32 & 73 & 1025 & 1130 & 1.12 \\
Circulate false sexual rumors about you & 28 & 36 & 1072 & 1136 & 1.08 \\
Send annoying romantic texts on phone & 54 & 78 & 1024 & 1156 & 1.16 \\
Send embarassing phonographic photos & 11 & 17 & 1080 & 1108 & 0.97 \\
Pass comments about look that is sexual & 105 & 134 & 861 & 1100 & 1.31 \\
Send disturbing texts and emails & 84 & 79 & 989 & 1149 & 1.22 \\
Ask for outing and you say no & 58 & 166 & 950 & 1084 & 1.34 \\
Threaten for refusing relationship & 22 & 52 & 1001 & 1075 & 1.15 \\
\hline
\end{tabular}

\section{Responses to Hypothetical Scenarios}

Table 2 shows how students perceived the hypothetical scenarios on possibilities of occurrence of the $\mathrm{SH}$ descriptions on the campus. Scenarios 4 and 8 involving male student victimizing female student to concede to sexual-related intimacy are perceived by a high percentage with most likelihood of happening $(71.5 \%, 54.6 \%)$ although not labelled as SH $(20.9 \%, 39.1 \%)$. Scenarios 2 and 10 involving females as the perpetuator are perceived least likelihood to happen ( $27 \%$ and $21 \%$ ) and labelled least as sexual harassment. Descriptions involving male lecturers against female students as victims stood out with definitive response of high likelihood of occurrence and labelled by a high percentage as $\mathrm{SH}$ behaviour. Scenario 1, 5 and 9 containing SH elements with promises of mark reward or access to questions are perceived with high likelihood of occurrences $(53 \% ; 47.7 \% ; 38.4 \%)$ and labelled as $\mathrm{SH}$ behaviour by a high percentage of respondents $(73.8 \%$; $62.9 \% ; 66.2 \%)$ respectively. Additionally, scenario 6 involving deliberately failing a student in return for turning down sexual request is considered to have high likelihood of occurrence $(51 \%)$ and perceived as $\mathrm{SH}$ behavior by a high percentage of respondents $(66 \%)$.

Table 2: \% Responses to Scenarios on $\mathrm{SH}$ Behaviour

\begin{tabular}{|c|c|c|c|c|}
\hline Scenarios & 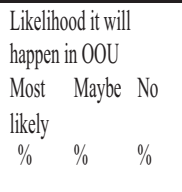 & $\begin{array}{l}\text { Have you } \\
\text { experienced } \\
\text { similar situation } \\
\text { Yes } \quad N_{0} \\
\% \\
\%\end{array}$ & 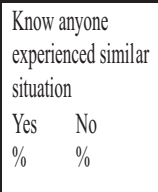 & $\begin{array}{ll}\text { Yes } & \text { No } \\
\% & \%\end{array}$ \\
\hline Scenario 1 & $\begin{array}{lll}53.0 & 37.7 & 7.0\end{array}$ & $\begin{array}{ll}12.3 & 86.4 \\
\end{array}$ & \begin{tabular}{|ll}
65.3 & 34.7
\end{tabular} & \begin{tabular}{|ll}
73.8 & 10.3 \\
\end{tabular} \\
\hline Scenario 2 & $\begin{array}{lll}15.9 & 34.1 & 27.8\end{array}$ & \begin{tabular}{|ll}
3.0 & 95.4 \\
\end{tabular} & \begin{tabular}{|ll}
6.0 & 91.4 \\
\end{tabular} & $\begin{array}{ll}65.9 & 12.9\end{array}$ \\
\hline Scenario 3 & $\begin{array}{lll}44.7 & 14.7 & 10.3\end{array}$ & $\begin{array}{ll}4.3 & 92.1\end{array}$ & \begin{tabular}{|ll}
45.6 & 50.8
\end{tabular} & $\begin{array}{ll}75.2 & 8.6\end{array}$ \\
\hline Scenario 4 & $\begin{array}{|lll|}20.9 & 71.5 & 5.3 \\
\end{array}$ & $\begin{array}{ll}29.8 & 67.5 \\
\end{array}$ & \begin{tabular}{|ll}
51.0 & 46.0
\end{tabular} & $\begin{array}{ll}20.9 & 53.6\end{array}$ \\
\hline Scenario 5 & $\begin{array}{lll}47.7 & 41.1 & 6.6\end{array}$ & $\begin{array}{ll}5.6 & 90.1\end{array}$ & \begin{tabular}{|ll}
49.5 & 50.2
\end{tabular} & $\begin{array}{ll}62.9 & 13.9\end{array}$ \\
\hline Scenario 6 & $\begin{array}{|lll|}36.8 & 51.3 & 7.3 \\
\end{array}$ & $\begin{array}{ll}6.5 & 89.4\end{array}$ & \begin{tabular}{|ll}
43.8 & 56.2
\end{tabular} & $\begin{array}{ll}66.2 & 12.9\end{array}$ \\
\hline Scenario 7 & $\begin{array}{|lll|}26.5 & 47.7 & 20.2\end{array}$ & $\begin{array}{ll}9.6 & 84.4\end{array}$ & \begin{tabular}{|ll}
11.6 & 81.8 \\
\end{tabular} & $\begin{array}{ll}41.7 \quad 26.5 \\
\end{array}$ \\
\hline Scenario 8 & $\begin{array}{|lll|}31.1 & 54.6 & 7.6 \\
\end{array}$ & $\begin{array}{ll}13.2 & 79.5 \\
\end{array}$ & $\begin{array}{|ll|}25.5 & 67.5 \\
\end{array}$ & $\begin{array}{ll}39.1 & 32.8 \\
\end{array}$ \\
\hline Scenario 9 & $\begin{array}{lll}38.5 & 43.7 & 10.6\end{array}$ & $\begin{array}{ll}7.6 & 84.4 \\
\end{array}$ & $68.5 \quad 31.5$ & 66.210 .6 \\
\hline Scenario 10 & \begin{tabular}{lll|}
37.1 & 45.5 & 10.6
\end{tabular} & $\begin{array}{ll}6.3 & 86.4\end{array}$ & $\begin{array}{|ll|}15.6 & 77.2 \\
\end{array}$ & $\begin{array}{ll}54.3 & 14.2\end{array}$ \\
\hline
\end{tabular}


Furthermore, Table 2 shows that students generally claimed not to have had direct personal experiences of the behaviors as described in the scenarios, although a high percentage indicated to know persons that experienced similar situations. For example scenarios 1, 5 and 9 (indicated as most likelihood of occurrence) are reported to have been experienced by more student victims that they know.

It is interesting to note what behaviours the students labelled as $\mathrm{SH}$ victimization. Scenario 4, 7, 10 involving actions between students, even though perceived by many students with high likelihood of occurrence, were least labelled as $\mathrm{SH}$. On the other hand, behaviours involving lecturers are labelled as $\mathrm{SH}$ by a high percentage of which scenarios 1 and 3(Table 3) top the list (see Table 3).

Table 3: SH elements in scenarios 1 and 3.

\begin{tabular}{|c|c|}
\hline Scenario 1 & Scenario 3 \\
\hline Status: Male Lecturer- female student & Status: Male lecturer-female student \\
\hline Setting - office & Setting: Office area \\
\hline Bait- raised issue about assignment & Bait: requested her to collect a ll the forms \\
\hline Kept her waiting & Made her class rep. \\
\hline Verbal actions: He commented 'I like you' & Verbal action: Thanked her for a great job \\
\hline Asked her out for a drink & Asked her jokingly'"You are beautiful' \\
\hline Asked her to see him & He said jokingly "I lke your red bra" \\
\hline Be my good girl & Physical action: smiled at her \\
\hline Physical actions: got close & gave her a peck on the palm \\
\hline Touch ed her body & closed office door against her \\
\hline Initial reaction: She tried to play it down & kissed her and squeezed her breast \\
\hline Student response: tried to avoid him & Initial reaction: she tried to dismiss the remarks. \\
\hline \multirow{2}{*}{$\underline{\text { Reward: promise: "A grade" }}$} & She was worried \\
\hline & $\begin{array}{l}\text { Threat: Told her not to say it out, otherwise he will } \\
\text { make a case against her with the authority }\end{array}$ \\
\hline
\end{tabular}

Respondents were asked to indicate what they would do in similar situations as described in the scenario. Two strategies stood out in almost all the cases involving lecturers - prayer and telling friends/pastor. On the other hand, for the cases involving students, they indicated avoiding the situation or telling friends. No one mentioned reporting to the authority as a way of getting around the victimization cases.

\section{Discussion}

The findings of this study provide further evidence on the existence of sexual harassment victimization in education settings. The results are consistent with other studies in Nigeria (Omonijo et al., 2013; Taiwo, Omole \& Omole, 2014) and other countries, thus affirming the global nature of the problem. However, the gratifying finding of the present study is the fact that students perceive that $\mathrm{SH}$ behavior, though existing, is not rampant in its scale of occurrence in OOU. This finding is noteworthy, and may not be unconnected with the fact that the University Management took strategic actions to sanitize the system and restore a reasonable level of professionalism in the recent past. However, the fact that there still exist occurrences of sexual harassment should not be ignored. This is because every case of sexual harassment creates social and psychological impediment for the victim to access a protected learning environment. Experiences of sexual harassment in schools has been associated with avoidant behaviours, low self-esteem, feeling unsafe at school and low life satisfaction (Gruber \& Fineran, 2007). Moreover, it negatively impact on the victims ability to participate in and benefit from the educational programme, creates a hostile and offensive work/school environment (Gruber \& Fineran, 2007; Pina et al., 2009) as well as presents traumatizing experience for those who are victimized (Fineran \& Bolen, 2006).

The majority of respondents in this study indicated that they formed their opinion from what they heard people talk about or what they saw others experienced rather than direct personal experience. Even with the scenarios that were described, the majority of students indicated that they had no direct experience but knew of someone that had similar experience. This further confirms the findings in previous studies that victims do not like to divulge direct experience of sexual harassment or report their victimization because of "lack of trust, lukewarm action on the part of the authority, and possibility of shifting blame on the offended. (Leach, 2013). Other reasons that victims are reluctant to open up are humiliation, embarrassment, anger, fear and guilt.

The students indicated that they would rather confide in religious leaders or friends or pray rather than report to University authority if in similar situations as described in the scenario. No wonder it is extremely difficult to obtain reliable evidence on the scale of campus-based sexual harassment, and would require that other innovative reporting procedure that protects identity of victims are adopted.

Of the reported experiences of $\mathrm{SH}$ behaviours that were presented, the noteworthy frequent items include "making annoying jokes about looks", "touching intimate body parts in disrespectful way", "passing comment about look that is sexual" and "keep asking for outing even when the student says no". These behavior are features of a hostile-environment harassment. As defined by Willness (2007), a hostile-environment harassment is one in which a female/male student is subjected to repeated offensive and denigrating sexual comments and behaviour which can include unwelcomed sexual advances, requests for sexual favours and other verbal, nonverbal, or physical conduct of sexual nature by lecturer, another student, or a third party. Studies show that, in school settings and particularly between students, allegations of hostile-environment harassment are more commonplace than allegations of quid pro quo harassment (Stein, 2000) indicating that women are 
more likely to be the object of sexual jokes, remarks, or gestures (Hill \& Silva, 2005) and are more likely to be upset, feel embarrassed, angry, less confident, afraid, or worried by sexual assault (Hill \& Silva, 2005). However, it is gratifying that quid pro quo harassment or sexual cohesion was least frequent in Table 1 as shown by the low mean values (e.g., threaten to blackmail for refusing relationship $\bar{x}=1.09$; ask for sexual relationship with grade promises $\bar{x}=1.12$; offer grade or money for a date $\bar{x}=1.27$; and threaten to have sex or fail a course $\bar{x}=1.13$ ). This is because such harassment behavior impact negatively on the quality assurance mechanisms within the system of education and diminishes the value of assessment practices for certification.

An interesting pattern that emerged was the tendency of students generally not to label the scenario descriptions between students as $\mathrm{SH}$ behaviour, though reported to have high likelihood of occurrence. In the same vein, the two scenario descriptions involving females as the perpetrators were perceived with the least likelihood of occurrence. On the other hand, scenario descriptions involving male lecturers against female students came out strongly in their perceptions as most likelihood of occurrence and labelled by a high percentage of respondents as $\mathrm{SH}$ behaviour. These outcomes suggest that students' probably have low awareness that they can also be victims of peer SH, but only consider male lecturers as the perpetrators of SH. Finally, even though the findings in Table 1 show that a number of students generally did not directly experience quid pro quo harassment, a high percentage of the respondents labelled scenarios 1,3,5,9 which are descriptions of such harassment to have high likelihood of occurrence (Table 2) and also knew someone who had experienced similar situation. This is suggestive that management must not dismiss the fact that the behaviours could be occurring but students would probably concede if it is in their favour.

\section{Conclusion}

The results of this study have important implications for the university to foster an equitable and safe learning environment for all students by preventing sexual harassment victimization through anti-harassment policy, continued sensitization and training as well as grievance/reporting mechanisms, rather than managing the unethical behaviour. This study is exploratory and entails therefore certain limitations which future research can consider. For example, though using perception questionnaire and scenarios provided some useful information, nevertheless, applying direct interview technique and asking the participants to write their own real life story might have provided more credible evaluation of the campus climate. Combining quantitative and qualitative data would enhance the validity of a study of this nature and can provide a broader perspective of sexual harassment behavior on the campus.

\section{Recommendations}

Following are a few recommendations that can help deal with the issue of sexual harassment in Olabisi Onabanjo University and by implications Universities in Nigeria.

1. Develop Policy on Sexual Harassment and Sexual Misconduct: The key to dealing with sexual harassment/violence on the campus is for Management to label the behaviour offensive, and spell out explicit sanctions/punitive measures for perpetrators in the policy, and this should be well publicized to send signals to the community that perpetrators of unethical sexual acts will incur penalty.

2. Establish formal reporting/monitoring mechanisms: This is an attempt to establish grievance procedure and label sexual harassment (and other sexual misconduct) as offence of institutional concern.

3. Set up University support system: This is with a view to raising confidence level of students that the University cares for them and providing safety nets for all students.

4. Provide continued sensitization programme: This would help to build a community of staff and students with high level of awareness of sexual harassment as inequity issue and the wrong in acceptance of these unethical behaviours. More importantly, it will help quite a number of new and inexperienced lecturers that were employed in recent years without orientation or retreat trainings on the essence of professionalism and responsibility in relationships with students.

\section{Financial Support}

This research was supported by the TETFUND Institution Based Research (IBR) grant OOU/003/ 2017.

\section{References}

American Association of University Women (AAUW) (2001). Hostile Hallways: Bullying, teasing and sexual harassment in school. Newton: ASUW Educational Foundation.

Biden, S. 2010. Guardian.co.uk, Thursday 16Jan, 2010.

Britwum A. O. \& Anokye A. A. (2006). Confronting sexual harassment in Ghananian Universities. Centre for Development Studies, University of Cape Coast \& Ghana University press.

Buchanan, N. T., Bluestein, B. M., Nappa, A. C., Woods, K. C., \& Depatie, M. M. (2013). Exploring gender differences in body image, eating pathology, and sexual harassment. Body Image, 10(3), 352-360. http://dx.doi.org/10.1016/j.bodyim.2013.03.00 $\underline{4}$

Dastile, N. P. (2004). Victimisation of female students at the University of Venda with specific reference to sexual harassment and rape. Unpublished Master's Thesis. University of Pretoria. (Accessed online).

Dhlomo, T., Mugweni, R. M.,Shoniwa, G., Maunganidze, L., Sodi, T. (2012). Perceived sexual harassment among female students at a Zimbabwe institution of higher learning. Journal of Psychology in Africa, 2, 269-272. 
Eilsberg M. (2000). Candies in hell: Research and action on domestic violence against women in Nicaragua, Umea University, Sweden: Department of Public Health and Clinical Medicine.

Espelage D. L. \& Holt M. (2007). Dating Violence and Sexual Harassment across the Bully-Victim Continuum among Middle and High School Students. Youth Adolescence 799-811.

FAWE News, 8(3), Sept., 2000.

Fineran, S., \& Bolen, R. M. (2006). Risk factors for peer sexual harassment in schools. Journal of Interpersonal Violence, 21(9), 1169-1190.

Gruber, J., E., \& Fineran, S. (2007). The impact of bullying and sexual harassment on middle and high school girls. Violence Against Women, 13(6).

Herrera, M. C., Herrera, A., \& Expósito, F. (2014). Stop Harassment! Men's reactions to victims' confrontation. The European Journal of Psychology Applied to Legal Context, 6, 45-52. http://dx.doi.org/10.1016/j.ejpal.2014.06.006.

Herrera, María, Herrera, Antonio, Expósito, Francisca (2017). To confront or not to confront: Women's perception of sexual harassment. The European Journal of Psychology Applied to Legal Context. (http://dx.doi.org/10.4314/pelj.414i6.6. Accessed July 2017).

Hill, C., \& Silva, E. (2005). Drawing the line: Sexual harassment on campus. Washington, DC: American Association of University Women Educational Foundation. http://dx.doi.org/10.1016/j.adolescence.2009.0 1.011 .

Imonikhe, J, Aluede, O. O. \& Idogho, P. (2012). A Survey of Teachers' and Students' Perception of Sexual Harassment in Tertiary Institutions of Edo State, Nigeria. Journal of Asian Social Science, 8 (1): 268-273.

Keshwa, J. G (2014). Exploring the Causal Factors and the Effects of Sexual Harassment on Female Students at the Universities in Africa. An Overview. Mediterranean Journal of Social Sciences, 5,20, 28472852.

Leach, F. (2013). Corruption as abuse of power: Sexual violence in educational institutions. In G. Sweeny, K. Despota, S. Lindner (eds.). Transparency International, Global Corruption Report: Education. Abingdon, Oxon: Routledge, 88-98.

Mamaru, A., Getachew, K., Mohammed, Y. (2015). Prevalence of physical, verbal and nonverbal harassment and their association with psychological distress among Jimma University female students: A cross-sectional study. Ethiopian Journal of Health Sciences, 1, 29-38.

McMaster, L. E., Connolly, J., Pepler, D., \& Craig, W. M. (2002). Peer to peer sexual harassment in early adolescence: A developmental perspective. Development \& Psychopathology, 14(1), 91-105.
Mitchell, K. J., Ybarra, M. L., \& Korchmaros, J. D. (2014). Sexual harassment among adolescents of different sexual orientations and gender identities. Child Abuse \& Neglect, 38(2), 280-295. http://dx.doi.org/10.1016/j.chiabu.2013.09.008.

Norman, I. D., Aikins, M.,Binka, F. N. (2013). Sexual harassment in public medical schools in Ghana. Ghana Medical Journal, 3, 128-136.

Nwagbara, B. A. (2011). Campus Sexual violence in Nigerian Tertiary schools: Response and priorities. Presentation at SVRI Forum 2011: Moving the Agenda Forward.

Omonijo, Dare O., Uche, Onyekwere C. O., Nwadiafor, Kanayo L., \& Rotimi, Omolola A. (2013). A Study of Sexual Harassment in Three Selected Private Faith-Based Universities, Ogun-State, South-West Nigeria. Open Journal of Social Science Research, 1(9):250-263.

Petersen J. L, Hyde J.S. (2013) Peer sexual harassment and disordered eating in early adolescence. Development Psychol, 49:184-95.

Petersen, J. L., \& Hyde, J. S. (2009). A longitudinal investigation of peer sexual harassment victimization in adolescence. Journal of Adolescence, 32(5), 1173-1188.

Pina, A., Gannon, T., \& Saunders, B. (2009). An overview of the literature on sexual harassment: Perpetrator, theory, and treatment issues. Aggression and Violent Behavior, 14(2), 129-138. http://dx.doi.org/10.1016/j.avb.2009.01.002.

Sandler, B. R., \& Shoop, R. J. (Eds.) (1997). Sexual harassment on campus: A guide for administrators, faculty, and students. Needham Heights, MA: Allyn \& Bacon.

Schneider, K. T., Pryor, J. B., \& Fitzgerald, L. F. (2010). Sexual harassment research in the United States. In S. Einarsen, H. Hoel, D. Zapf, \& C. L. Cooper (Eds.), Bullying and harassment in the workplace: Developments in theory, research and practice (2nd ed.,). Boca Raton: CRC Press. pp. 245-260.

Smit D. \& V DU Plessis (2011). Sexual harassment in the education sector http://dx.doi.og/10.4314/ PELJ.v14i6.v6.

Stein, N. (2000). Sexual harassment in schools. Facing sexual harassment in K-12. New York: Teacher's College Press, Columbia.

Steinkamp, F. R., (2010). The prevalence of sexual harassment within a student sample of Stellenbosch University. Thesis presented in partial fulfilment of the requirements for the Degree of Master of Arts (Psychology) at Stellenbosch University.(Accessed online).

Omonijo, D. O.; Uche, O. C. O., Nwadiafor, K. L., Rotimi, O. A. (2013).A study of sexual harassment in three selected private faith-based Universities, Ogun State, Nigeria. Open Journal of Social Science research, 9, 2 . 
Taiwo, M. O., Omole O. C., \& Omole, O. E., (2014).Sexual Harassment and Psychological Consequence among Students in Higher Education Institution in Osun State, Nigeria . International Journal of Applied Psychology, 4(1): 13-18.

Taylor, Elizabeth A., Hardin, R. (2017) A gap in the sport management curriculum: An analysis of sexual harassment and sexual assault education in the United States. Journal of Hospitality, Leisure, Sport \& Tourism Education, 20, 65-75.

Till, F. (1990). Sexual harassment: $A$ report on the sexual harassment of students. Washington, D.C. National Advisory Council on Women's Educational Programs: U.S. Government Printing Office. Washington: DC: AAUW.
Willness, C., Steel, P., \& Lee, K. (2007). A meta-analysis of the antecedents and consequences of workplace sexual harassment. Personality Psychology, 60, 127-162. www.elsevier.es/ijchp

Vega-Gea, Esther, Ortega-Ruiz, Rosario, Sánchez, Virginia (2016). Sexual harassment in adolescence: Dimensions of the sexual harassment survey in boys and girls. International Journal of Clinical and Health Psychology. 16, 47-57. 